\title{
Development of the Market of Milking Parlors as a Factor of Competitiveness of Manufacturers of Equipment for the Dairy Industry
}

\author{
Kulumbegov Mikhail Mikhailovich \\ Martenovskaya Street, Moscow, Russia \\ m.kulumbegov@ya.ru
}

\begin{abstract}
Currently, there are a huge number of types of milking parlors and their configurations. The article presents the main definitions, studied the main equipment manufacturers, and compared the milking parlors "Herringbone" and "Rotary", as well as the main advantages and disadvantages of each.
\end{abstract}

Keywords: Equipment, milking parlor, rotary, herringbone, competitiveness, manufacturing enterprise

\section{Introduction}

Enterprises manufacturers of equipment are forced to use the most effective methods of production and modernization of technologies in order to increase their competitiveness. Currently, there is a huge number of European and Russian manufacturers of milking parlors. The European are "Afimilk», «Joz», «Serap», «Bioret», «Bauer», «GEA Farm», «FAN», «Siloking», «SAC» and others. To the Russian: LLC "Agrostroy", LLC "Dairy Systems", LLC "Agromoltechnika". Let's consider some of them in more detail. Afimilk is the global leader in developing, manufacturing and marketing advanced computerized systems for the modern dairy farm and for herd management. Since 1977, Afimilk has been a pioneer in the field, with the introduction of the first electronic milk meter. Since then, based on its strong research and development group, the company has continued to provide cutting-edge solutions for the milking parlor. The company's systems are installed and in use on thousands of farms in 50 countries across five continents. With hundreds of thousands of milk meters and millions of behavior sensors installed, Afimilk sets the standards for dairy farming and management around the globe (Afimilk, 2017). Founded in 1938, A/S S.A. Christensen \& CO. is today one of the leading companies in Europe specializing in the production of milking parlors and milking equipment. The company is a $100 \%$ Danish, family-owned, limited company. It is presently owned and led by the third generation of Christensens, Steen A. Christensen. Over the years, the company has developed into an international manufacturing and trading company that exports milking equipment, milking parlors and other products to more than 65 countries around the world. Exports presently account for more than $60 \%$ of total turnover (SAC, 2017).

The company "Agrostroy" is one of the leading and dynamically developing agricultural enterprises of the Udmurt Republic within the framework of the market for the production of equipment for cattle-breeding complexes and construction of objects of the agro-industrial sector. The main activities of the company:

- Design, manufacture and installation of equipment for dairy farms and livestock complexes;

- Construction of prefabricated frameless hangars (cowsheds, pigsties, granaries, vegetable stores, etc.).

- Reconstruction of the ITF.

Construction works are represented by the erection of turnkey complexes, their complete reconstruction, and major repairs. In turn, among the produced and sold equipment can be called milking equipment and milking halls, milk lines, stall equipment, as well as a number of other products. On the basis of the enterprise has its own production base, which is equipped with modern metalworking and diagnostic equipment. The use of the latest technologies and equipment makes it possible to provide high quality products: linear milk lines, milking parlors, feeding systems, drinking and manure removal, and some types of agricultural technology (Agrostroy, 2017). The company "Agromoltekhnika-Siberia" offers a wide range of modern equipment for animal husbandry: milking parlors, linear milk lines, milking plants, dairy farms, pig farms, as well as agricultural machinery of leading manufacturers from all over the world. In addition, the company offers a new line of business - the design and construction of prefabricated hangars using a unique technology. The company has the presence of its own production - so it guarantees the delivery of quality equipment at affordable prices. The production base is equipped with modern equipment and fully complies with European requirements. All products undergo thorough quality control, are certified and comply with international 
standards. The company constantly carries out work on modernization and improvement of the offered products and services. Possession of unique technologies allows improving the quality of products and promotes the constant expansion of the assortment (Agromoltechnika, 2017).

In the presence of a large herd, the capacity of the milking parlor acquires special significance for production efficiency. In other words, it is necessary to milk as many animals as possible per hour. First of all, a large milking parlor is required, but dimensions alone are not decisive for increasing productivity. The configuration of the stall and the whole farm plays a large role here, as well as the choice of the shape of the milking parlor. Some milk producers achieve the highest results on the milking "carousel", while others get no less impressive results using traditional milking parlors (Transfaire, 2017). Milking parlor - automated equipment for milking cows. Depending on a number of factors, such as the number of cattle, the efficiency of the enterprise, milking parlors of the following types are used: stationary or mobile hall with different ways of housing cattle. The most popular models on the Russian market are Herringbone, Carousel and Parallel. Milking parlors are the most common type of hall due to their simplicity and high efficiency, and the relative ease of adaptation to new or existing premises. Milking parlor "Herringbone" is a complex of automatic systems, including the possibility of individual design, high throughput and quick change of animals. In the complete set of the hall: exit gate, vacuum pump, vacuum line (stainless steel), washing system, milking machines, centrifugal milk pump, milk collector and transport milk line. Cows in such a milking parlor can be located at different angles - from $30^{\circ}$ to $90^{\circ}$. The field of installation of basic systems milking parlor in the future can be retrofitted with additional elements. Separate options are used in the offline mode, allowing you to track the milk yield of each individual and use the individual optimization of the milking process to increase milk yield. Depending on the amount of free space, the milking parlor is equipped with a chest stop, corner feeders or fixing bars (GEA, 2017).

Milking parlor "Carousel" is completely different from the one presented above. Its main feature is the presence of a constantly moving platform, on which animals in turn rise. The operator attaches equipment to each cow. Animals are sent to him on a moving platform at a given speed. Thus, in comparison with the "Herringbone", "Carousel" provides greater productivity in one hour of time. The operator with the help of the control panel independently controls all functions of the platform, including automatic adjusting gates, feeding system, etc. Milking parlor "Parallel" is the product of the logical evolution of the milking parlors of the previous types: here the animals are already at an angle of 90 degrees to the milking hole, that is, exactly back to the operator. The milking devices are connected not from the side, but between the rear legs of the animal. Due to this setting of animals, the length of the milking place is reduced to $0.75 \mathrm{~m}$; the area of the milking parlor is significantly saved. This arrangement allows the installation of up to 50 cows in a row, that is, up to 100 cows $(2 \times 50)$ can be milked simultaneously. Most of the halls of the "parallel" type are equipped with an individual exit system, which facilitates the rapid release of the hall. Along with all the advantages of the halls of the "parallel" type, they also have a disadvantage: because of the peculiarity of setting animals for milking, the operator is inconvenient to work with the front quarters of the udder. This type of plant is today the best solution for large farms - 500-2000 cows. The throughput of installations of this type reaches 4.5 cows per hour per seat (Agrarian Review, 2011). Let's make a comparative analysis of advantages and disadvantages of each type. The data are presented in the form of a table 1.

The correctness of the choice depends on the design of the buildings and the operation of the barn equipment, but the personal preferences of the farm owner are more important here. All types of milking parlors can be changed to a large extent to suit specific needs and requirements. Most equipment suppliers offer competent advice on the configuration and selection of the type of milking parlor in order to ensure high productivity and optimum efficiency. Machine milking increases productivity and is aimed at improving the quality of milk. The negative factors of this process include the sharp incidence of cows with mastitis, which is caused by poor selection of cows to the technology of mechanized milking due to mismatch of udder parameters. At present, machine milking of cows on farms is about $90-95 \%$. This is due to the transition of the industry to an industrial basis. In order to increase profitability of production, it is necessary to mechanize and automate all labor-intensive processes in the industry. Milking devices maximally improve to minimize the harmful effect on the mammary gland. 
Table 1: Advantages and disadvantages of milking parlors "Herringbone", "Carousel" and "Parallel"

\begin{tabular}{|c|c|c|}
\hline & Advantages & Disadvantages \\
\hline "Herringbone" & $\begin{array}{l}\text { - The length of the milking site does not } \\
\text { exceed } 1.25 \mathrm{~m} \text {, which increases the } \\
\text { operator's convenience and improves } \\
\text { - Its productivity. } \\
\text { - The area of the hall is reduced for } \\
\text { installation. } \\
\text { - Widerangeofinstallations. } \\
\text { - The speed of milking increases; } \\
\text { - Sizes from } 2 x 4 \text { places to } 2 \times 24 \text { seats; } \\
\text { - Automate work with the herd; } \\
\text { - High degree of mechanization of } \\
\text { milking. }\end{array}$ & $\begin{array}{l}\text { - Low productivity when used on groups } \\
\text { of cows with different productivity and } \\
\text { speed of milk yield. } \\
\text { - The need to form cows in groups with } \\
\text { the same duration of milk yield. } \\
\text { - Number of milking places is not more } \\
\text { than } 28 \\
\text { - Effectively apply on farms with a } \\
\text { livestock of up to } 400 \text { animals. }\end{array}$ \\
\hline "Rotary" & $\begin{array}{l}\text { - The flowing technology of the milking } \\
\text { process. } \\
\text { - Maximum productivity from the } \\
\text { calculation of the serviced livestock by } \\
\text { one operator per unit of time. } \\
\text { - Effective work, independent of the } \\
\text { number of zoo technical groups of } \\
\text { cows in the stall room. }\end{array}$ & $\begin{array}{ll}\text { - } & \text { Increased foquirements for } \\
\text { construction and installation work. } \\
\text { - Complexity of equipment and high cost } \\
\text { per one milking place. }\end{array}$ \\
\hline "Parallel" & $\begin{array}{l}\text { - Minimal milking front; } \\
\text { - } \text { High intensity of the milking operator; } \\
\text { the cost of equipment comparable to } \\
\text { productivity; } \\
\text { - A wide range of sizes - a wide range of } \\
\text { served livestock; } \\
\text { - As a rule, a stronger frame structure } \\
\text { designed for the most intensive use }\end{array}$ & $\begin{array}{l}\text { Increased requirements for the width } \\
\text { of the room; } \\
\text { - Increased requirements for the shape } \\
\text { of the udder; }\end{array}$ \\
\hline
\end{tabular}

The most popular milking machines in Russia are two-stroke (carry out milking in two cycles: sucking and squeezing) and three-stroke (carry out milking in three cycles: sucking, squeezing and resting). They work by the principle of sucking milk with a vacuum. Milking devices consist of a pulsator, collector, tea cups, a set of rubber tubes and hoses, viewing devices and clamps. The function of the pulsator in the milking machine is to convert the permanent vacuum into an alternating vacuum, and the function of the collector is to distribute vacuum and collect milk from the tea cups. A teat cup is one of the most important parts of a milking plant, which consists of four glasses, hoses and a collector, thanks to which the milking process is carried out. Glasses have a complex device, inside which are inserted rubber tubes - between them a sealed inter-walled chamber is formed. Two tubes are connected to the glass: the first is connected to the inner (sucker) chamber, and serves to suck the milk (this is the milk pipe), the second one with the interstitial chamber, and serves to create vacuum pulsations in the chamber (Miass Milking Plant, 2017). Milking devices are classified according to different signs. For convenience, we will present them in the form of a circuit (Fig. 1). On the basis of studying the process of milking cows, we can formulate the basic requirements that modern milking machines should meet:

- $\quad$ Optimization of milking speed;

- $\quad$ Stimulation of the milk yield reflex;

- $\quad$ Safety in case of overexposure of glasses on the nipples of a cow;

- $\quad$ To signal the successful end of the milking process and to turn off at the end of the process. 


\section{Framework}

Figure 1: Classification of milking machines

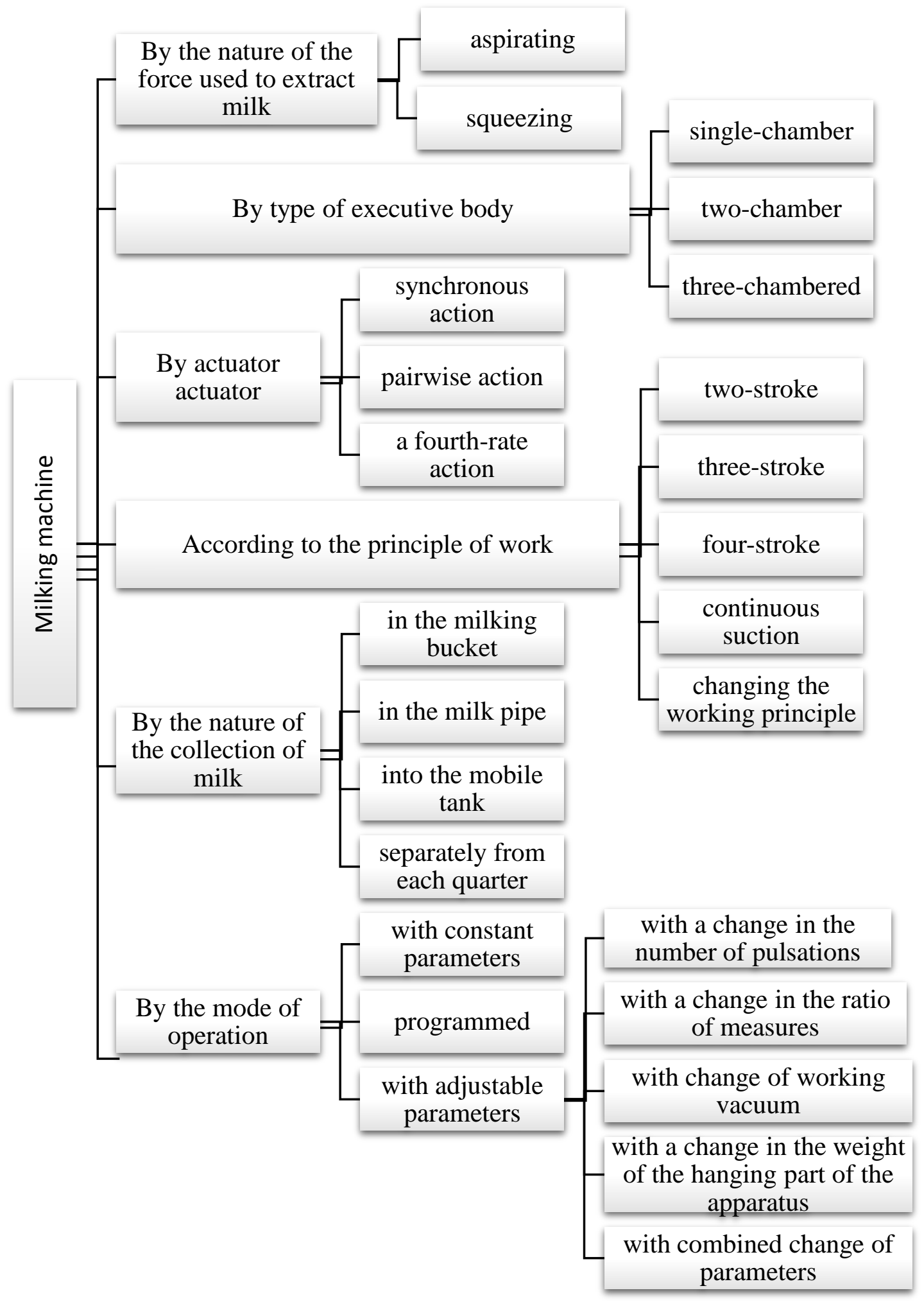




\section{Conclusion}

Due to the high wear and tear of equipment and their modernization at many enterprises of our country, as well as the need to introduce integrated mechanization of technological processes due to the high labor intensity in the production of milk, the demand for this equipment is growing. Transfaire Group of Companies has supplied to the Russian market more than 4 milking parlors in 2015-2017: «Novomarkovskoye», «Novoladozhsky», «NovoyeVremya», «Arkhangelskoe» and others1. This equipment meets all quality standards at the international level. Existing proposals in our market differ technical and economic parameters, therefore any investment project assumes the choice of the head and specialists the most suitable for the type and size of the milking installation, taking into account prices and other factors. From the right choice of technology, equipment and services, the quality of milk, the volume and cost of production and, ultimately, the profit received by the economy, largely depend on milk. The technology should promote the intensification of milk production, retaining its main purpose - to ensure the receipt of high-quality and cheap products, preserve animal health, increase labor productivity.

\section{References}

Magazine: "Agrarian Review", No. 1 (23), "Independent Agrarian Press" Publishing House, 2011

The company "Agromoltechnika" [Electronic resource]. - Access mode: http://sib-agro.com/doilnyj-apparat (Date of circulation: 04/09/2017).

The company "Agrostroy" [Electronic resource]. - Access mode: http://korovnik.biz/about/ (Date of circulation: 02.09.2017).

The company "Afimilk" [Electronic resource]. - Access mode: http://www.afimilk.com/about (Date of circulation: August 30, 2017).

The company "SAC" [Electronic resource]. - Access mode: http://www.sacmilking.com/company.aspx (Date of circulation: August 31, 2017).

The company "Transfaire" [Electronic resource]. - Access mode: http://www.transfaire.ru (Date of circulation: July 15, 2017)

International concern GEA [Electronic resource]. - Access mode: http://www.gea-market.ru (Date of circulation: 02.08.2017)

Miass Milking Plant [Electronic resource]. - Access mode: http: //mozdo.rf/node/1544 (Date of circulation: 02.09.2017) 